\title{
Income-related disparities in private prescription drug coverage in Canada
}

\author{
Talshyn Bolatova BSc, Michael R. Law PhD
}

\section{Abstract}

Background: Canada does not have universal public coverage for prescription drugs, which leaves an important role for private insurance plans. However, we do not have recent data on the characteristics of Canadians who report holding such coverage, particularly differences based on household income. We performed a study to examine the relation between household income and private drug insurance coverage in Canada.

Methods: We used data from the 2015-2016 cycle of the Canadian Community Health Survey to investigate the relation between household income and holding private drug insurance. We constructed modified multivariate Poisson regression models with robust error variances, including several potential confounders.

Results: Overall, $59.4 \%$ of respondents reported having private drug insurance. We found a strong dose-response relation between household income level and private drug insurance coverage: $19.8 \%$ of those with a household income less than $\$ 20000$ reported private coverage, compared to $76.2 \%$ of those with a household income of $\$ 80000$ or more.

Interpretation: Higher-income households are much more likely to hold private drug insurance coverage in Canada. This likely contributes to differential access to medicines and health outcomes by different income groups.

anada has a universal health insurance plan that covers medically necessary physician services and hospital stays. However, expenses for prescription drugs are not included in the universal plan and are instead covered by a patchwork of public and private drug insurance plans and out-of-pocket payments by patients. ${ }^{1}$ Private insurance companies accounted for $\$ 12.1$ billion in spending on prescription drugs in 2017 , representing $36 \%$ of total spending on prescription medicines. ${ }^{2}$ Despite the importance of private insurance in the financing of prescription drugs, there is a growing concern that the ability to access private insurance benefits outside of the universal health care system is related to socioeconomic status in Canada, leaving more vulnerable groups without coverage. ${ }^{3}$

In countries where health care services are predominantly covered through private insurance policies, there is an income- and health-related gradient whereby people with higher income and better health are more likely to purchase private health coverage. ${ }^{4-6}$ In the Canadian setting, the relation between income and private insurance coverage has been studied for dental and vision care coverage. ${ }^{7,8}$ These studies have shown significant associations between having a higher income and holding private insurance coverage. For example, Locker and colleagues ${ }^{7}$ found that only $17 \%$ of respondents with low household income reported having private dental insurance, compared to $80 \%$ of those with high household incomes. Similarly, Ngo and colleagues ${ }^{8}$ reported that the number of people with vision coverage in low- to moderateincome groups was half that in middle- and high-income groups. As a result, the "working poor" are thought to be a key group lacking effective drug coverage. ${ }^{3}$

With respect to prescription drugs, previous research has tended to focus on the impact of private drug insurance on inequities in overall use and on medication use for chronic conditions among older people..$^{3,4,9,10}$ Overall, these studies have shown that people with private drug insurance were more likely to visit physicians and fill prescription medications than those without insurance. However, to our knowledge, no recent studies have reported the relation between private drug insurance coverage and household income in Canada. Increased household share of spending on private insurance in

Competing interests: Michael Law has consulted for Health Canada, the Hospital Employees' Union and the Conference Board of Canada, and has provided expert witness testimony for the Attorney General of Canada. No other competing interests were declared.

This article has been peer reviewed.

Correspondence to: Michael Law, michael.law@ubc.ca

CMAJ Open 2019. DOI:10.9778/cmajo.20190085 
general, ${ }^{11}$ increased inequality and subsequent increase in the demand for private insurance, ${ }^{12}$ and evidence of cost-related nonadherence to prescription drugs ${ }^{13-15}$ provide a rationale for updating our knowledge in this area. Therefore, we examined the relation between household income and private drug insurance coverage in Canada.

\section{Methods}

\section{Study design}

We used data from the 2015-2016 cycle of the Canadian Community Health Survey (CCHS), a cross-sectional survey that collects information from the community-dwelling Canadian population. ${ }^{16}$ This CCHS cycle had 109659 respondents aged 12 years or more who resided in private dwellings, with a response rate of $59.5 \% .{ }^{16}$ The sample was collected by means of multistage cluster sampling and is representative of $98 \%$ of the population. ${ }^{16}$

\section{Analytical sample}

Our sample included people aged 12 years or more with valid responses to the CCHS question asking about prescription drug insurance status, the type of drug coverage and all confounding variables (those who responded "don't know," "refused to answer" or "not stated" were excluded).

\section{Study variables}

We constructed a binary outcome variable for self-reported private drug insurance coverage through a series of questions. Respondents were classified as having private drug insurance if they 1) responded "Yes" to the question "Do you have insurance that covers all or part of your prescription medication?" and 2) responded that it was either "employersponsored" or "sponsored through an association/private plan." Those who reported holding a government-sponsored plan or having no coverage were considered not to have private drug coverage. We did not study the availability of public drug coverage in our study, as prior work showed significant underreporting among people known to be covered under existing public plans; therefore, we considered these responses unreliable. ${ }^{17}$

Our main explanatory variable for this analysis was selfreported household income based on 5 categories $(<\$ 20000$, $\$ 20$ 000-\$39 999, \$40 000-\$59 999, \$60 000-\$79 999, $\geq \$ 80000)$. We also included a range of confounding variables, including age (grouped in 10-yr intervals), sex, province, number of chronic conditions $(0,1$ or $\geq 2)$, self-reported ethnicity (white, visible minority), immigration status (landed immigrant or nonpermanent resident; Canadian born) and highest level of educational attainment (less than secondary school, secondary school graduate, some postsecondary education, postsecondary certificate).

\section{Statistical analysis}

As the prevalence of the outcome was high (> 10\%), we used a modified Poisson model. ${ }^{18}$ With this model, the unbiased prevalence ratio $(\mathrm{PR})$ can be measured directly. ${ }^{18-20} \mathrm{We}$ con- ducted both unadjusted bivariate analyses to assess the relation between the outcome and exposure variables, and a multivariate adjusted model. All models used robust error variances, and we used survey weights for all statistical analyses to account for the survey sampling design.

\section{Ethics approval}

Ethics approval was not required for this study as it used a publicly available data set.

\section{Results}

\section{Sample characteristics}

Of the 109659 survey respondents, 97008 (88.5\%) had valid and nonmissing responses to all study questions (Figure 1). The overall study sample was equally distributed between males and females and was well distributed across age groups, with a smaller number of respondents in the oldest and the youngest groups (Table 1). A total of $78.0 \%$ of respondents identified as white, and $60.6 \%$ had completed postsecondary education.

Overall, 59.4\% of respondents self-reported as having private insurance that covered all or part of the cost of prescription medications. Nearly half of respondents (49.8\%) reported an annual household income of $\$ 80000$ or more, compared to $6.6 \%$ in the lowest category $(<\$ 20000)$. The proportion of respondents with private insurance increased with increasing annual household income: $19.8 \%$ of those in the lowest income band reported private drug insurance, compared to $49.0 \%$ in the $\$ 40000-\$ 59999$ income band and $76.2 \%$ in the highest income band (Table 1).

\section{Model results}

In both our unadjusted and multivariable modified Poisson regression models, the prevalence of private drug insurance was positively associated with annual household income. Compared to households with an annual income below $\$ 20$ 000, the PR of private drug insurance coverage versus no private insurance increased with each additional \$20 000 of household income: \$20 000-\$39 999, 1.49 (95\% confidence interval [CI] 1.36-1.64); \$40 000-\$59 999, 2.48 (95\% CI 2.26-2.71); \$60 000-\$79 999, 3.05 (95\% CI 2.79-3.34); and $\$ 80000$ or more, 3.85 (95\% CI 3.53-4.20) (Table 2). Model adjustment for age, sex, ethnicity, education level, province, immigration status and number of chronic conditions attenuated these results only to a small degree (1.55 [95\% CI 1.411.70] for income of $\$ 20000-\$ 39999$ to 3.22 [95\% CI $2.95-$ 3.51 for income of $\geq \$ 80$ 000]) (Table 2).

We found a statistically significant association between all of the other variables and private drug insurance coverage. In particular, the prevalence of private insurance coverage was higher among white people than among visible minorities, among school-age groups than among all other age groups, among Canadian-born people than among landed immigrants/nonpermanent residents, and among people who had completed postsecondary education than among those with lower education levels. The number of 


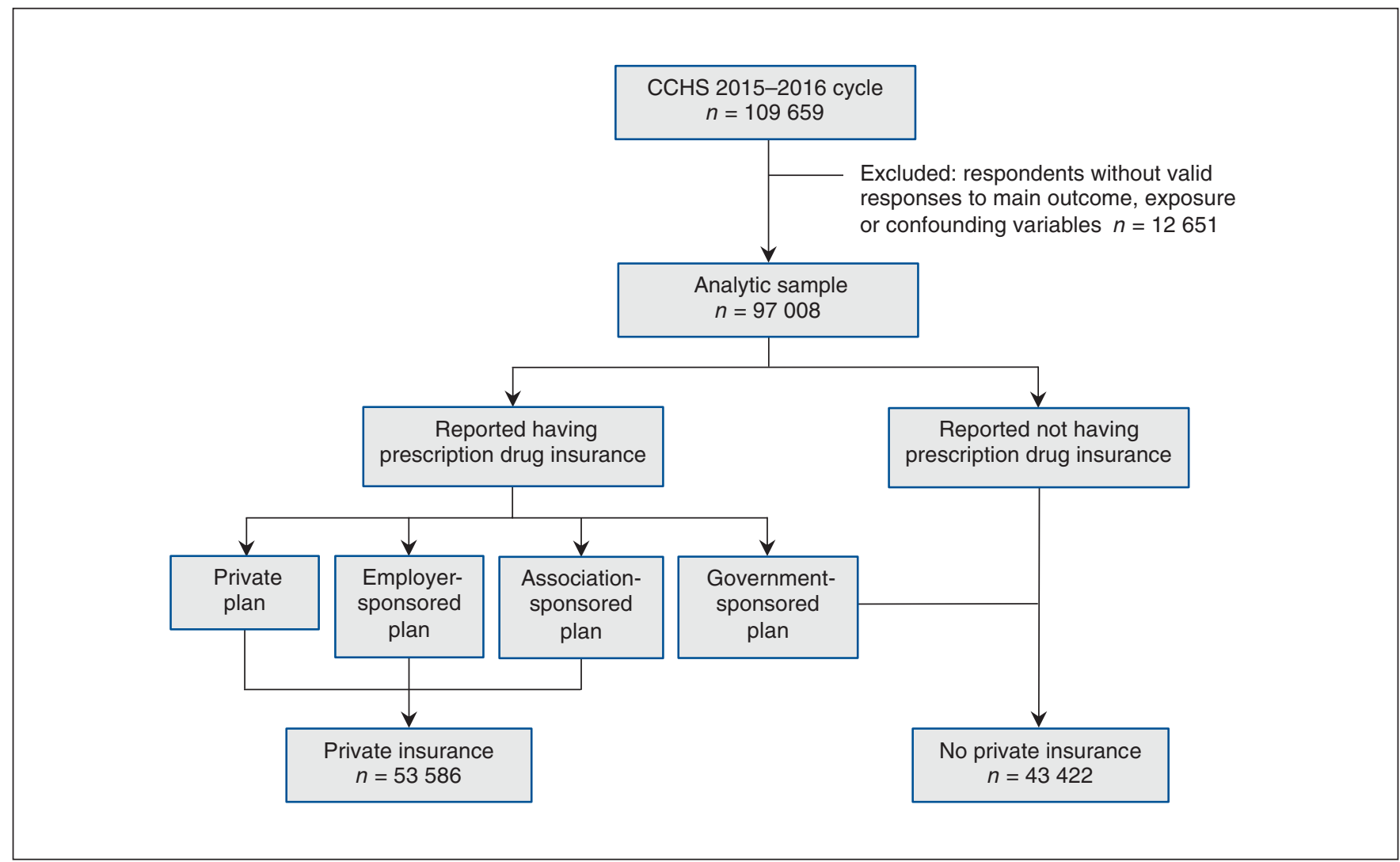

Figure 1: Selection of study sample from the Canadian Community Health Survey (CCHS) 2015-16.

chronic conditions was not significantly related to private insurance coverage in our final adjusted model.

\section{Age-stratified analysis}

In stratified analysis by age categories, the dose-response pattern of an increasing prevalence rate of employer and private insurance with increasing household income was strengthened for the working-age groups of 25-64 years (for income $\geq \$ 80000$, PR 4.02, 95\% CI 3.52-4.59) and for those aged 65 years or more (for income $\geq \$ 80000$, PR $4.51,95 \%$ CI 3.64-5.59) (Table 3). In contrast, the dose-response effect of increasing household income on the PR of employer and private insurance coverage was smaller in younger age groups.

\section{Interpretation}

We found that holding private prescription drug coverage was highly related to household income, with higher-income households being more than 3 times more likely to report holding such insurance than the lowest-income households. Our results are in line with those of previous studies conducted in Canada that also showed income-related disparities in holding private dental and vision coverage. ${ }^{7,8}$ Our results are also similar to those of older studies showing that Canadians with higher incomes were more likely to have private drug insurance. ${ }^{3}$ It is also notable that the characteristics we found to be associated with private drug insurance are similar to those of people who did not report cost-related nonadherence to prescription drugs and foregoing of other household spending to afford prescription medications. ${ }^{13}$

In the current study, people aged 18-24 years had slightly lower rates of insurance coverage than other age groups. This may have been due to the fact that people at this age become ineligible to be covered under their parent's employersponsored insurance coverage. Another plausible explanation is that people of this age group have not yet entered the workforce and therefore do not possess employment insurance or may be employed in industries with limited or no health coverage. ${ }^{21}$ The very low estimates of private insurance coverage among respondents aged 65 years or more is likely due to their retirement and subsequent loss of their employer-sponsored insurance plan.

\section{Limitations}

Although we used high-quality data from the CCHS drawn from a representative sample of Canadians, our study has limitations worth noting. The cross-sectional nature of the study cannot, of course, establish causal relations owing to the potential for confounding from unmeasured variables. Another limitation arises from the self-reported nature of some of sensitive variables such as income. If this led some households to bias their responses toward a more socially desirable response, it may have biased our results. We also are unable to quantify any underreporting of private insurance by 


\begin{tabular}{|c|c|c|c|c|}
\hline Characteristic & $\begin{array}{c}\text { No. of } \\
\text { respondents } \\
n=97008\end{array}$ & $\begin{array}{l}\text { Weighted } \\
\text { proportion of total } \\
\text { population, } \%\end{array}$ & $\begin{array}{l}\text { Weighted } \\
\text { proportion with } \\
\text { private drug } \\
\text { insurance, } \%\end{array}$ & $\begin{array}{l}\text { Estimated } \\
\text { proportion with } \\
\text { private drug } \\
\text { insurance, \% }\end{array}$ \\
\hline \multicolumn{5}{|l|}{ Annual household income, \$ } \\
\hline$<20000$ & 8762 & 6.6 & 2.2 & 19.8 \\
\hline $20000-39999$ & 17553 & 14.3 & 7.1 & 29.5 \\
\hline $40000-59999$ & 16128 & 15.0 & 12.3 & 49.0 \\
\hline $60000-79999$ & 13435 & 14.3 & 14.5 & 60.4 \\
\hline$\geq 80000$ & 41130 & 49.8 & 63.8 & 76.2 \\
\hline \multicolumn{5}{|l|}{ Sex } \\
\hline Male & 44867 & 49.3 & 49.9 & 60.1 \\
\hline Female & 52141 & 50.7 & 50.1 & 58.8 \\
\hline \multicolumn{5}{|l|}{ Age, yr } \\
\hline $12-17$ & 7522 & 7.1 & 8.4 & 71.0 \\
\hline $18-24$ & 6012 & 9.7 & 8.8 & 54.5 \\
\hline $25-34$ & 12672 & 16.5 & 18.0 & 64.8 \\
\hline $35-44$ & 12538 & 15.0 & 18.3 & 72.7 \\
\hline $45-54$ & 13972 & 17.0 & 20.4 & 71.7 \\
\hline $55-64$ & 17186 & 16.2 & 17.4 & 63.8 \\
\hline $65-74$ & 16039 & 11.6 & 5.9 & 30.2 \\
\hline$\geq 75$ & 11067 & 7.0 & 2.6 & 21.8 \\
\hline \multicolumn{5}{|l|}{ Ethnicity } \\
\hline White & 85891 & 78.0 & 80.1 & 61.0 \\
\hline $\begin{array}{l}\text { Nonwhite (Aboriginal/other visible } \\
\text { minority) }\end{array}$ & 11117 & 22.0 & 19.9 & 53.8 \\
\hline \multicolumn{5}{|l|}{ Education } \\
\hline Less than secondary school graduation & 21144 & 17.8 & 14.2 & 47.6 \\
\hline $\begin{array}{l}\text { Secondary school graduation, no } \\
\text { postsecondary education }\end{array}$ & 20784 & 21.7 & 19.8 & 54.3 \\
\hline $\begin{array}{l}\text { Postsecondary certificate diploma/ } \\
\text { university degree }\end{array}$ & 55080 & 60.6 & 66.0 & 64.7 \\
\hline \multicolumn{5}{|l|}{ Province } \\
\hline British Columbia & 12741 & 13.1 & 12.5 & 56.8 \\
\hline Alberta & 11933 & 11.6 & 13.4 & 68.4 \\
\hline Saskatchewan & 3988 & 2.9 & 3.1 & 63.9 \\
\hline Manitoba & 4504 & 3.2 & 3.5 & 64.7 \\
\hline Ontario & 29513 & 38.7 & 38.2 & 58.7 \\
\hline Quebec & 21285 & 23.7 & 22.1 & 55.4 \\
\hline New Brunswick & 3007 & 2.1 & 2.3 & 65.4 \\
\hline Nova Scotia & 4347 & 2.7 & 2.9 & 62.6 \\
\hline Prince Edward Island & 1695 & 0.4 & 0.4 & 61.1 \\
\hline Newfoundland and Labrador & 2680 & 1.4 & 1.5 & 62.1 \\
\hline Yukon Territory & 725 & 0.1 & 0.1 & 49.1 \\
\hline Northwest Territories & 444 & 0.1 & 0.1 & 62.1 \\
\hline Nunavut & 146 & 0.0 & 0.0 & 77.3 \\
\hline \multicolumn{5}{|l|}{ No. of chronic conditions } \\
\hline 0 & 41234 & 49.1 & 53.9 & 65.3 \\
\hline 1 & 24892 & 25.3 & 25.7 & 60.4 \\
\hline$\geq 2$ & 30882 & 25.6 & 20.3 & 47.2 \\
\hline \multicolumn{5}{|l|}{ Citizenship } \\
\hline $\begin{array}{l}\text { Landed immigrant/nonpermanent } \\
\text { resident }\end{array}$ & 15913 & 26.0 & 22.9 & 52.3 \\
\hline Nonimmigrant (Canadian born) & 81095 & 74.0 & 77.1 & 62.0 \\
\hline
\end{tabular}


Table 2: Unadjusted and multivariate parameter estimates from a modified Poisson model estimating the association of sociodemographic characteristics with private drug insurance coverage

\begin{tabular}{|c|c|c|}
\hline \multirow[b]{2}{*}{ Variable } & \multicolumn{2}{|c|}{ Prevalence ratio $(95 \% \mathrm{Cl})$} \\
\hline & Unadjusted & Adjusted \\
\hline \multicolumn{3}{|l|}{ Annual household income, \$ } \\
\hline $20000-39999$ & $1.49(1.36-1.64)$ & $1.55(1.41-1.70)$ \\
\hline $40000-59999$ & $2.48(2.26-2.71)$ & $2.36(2.16-2.58)$ \\
\hline $60000-79999$ & $3.05(2.79-3.34)$ & $2.75(2.52-3.00)$ \\
\hline$\geq 80000$ & $3.85(3.53-4.20)$ & $3.22(2.95-3.51)$ \\
\hline$<20000$ & 1 & 1 \\
\hline \multicolumn{3}{|l|}{ Sex } \\
\hline Female & $0.98(0.96-0.99)$ & $1.03(1.01-1.04)$ \\
\hline Male & 1 & 1 \\
\hline \multicolumn{3}{|l|}{ Age, yr } \\
\hline $18-24$ & $0.77(0.73-0.80)$ & $0.66(0.63-0.70)$ \\
\hline $25-34$ & $0.91(0.88-0.94)$ & $0.75(0.71-0.78)$ \\
\hline $35-44$ & $1.02(0.99-1.06)$ & $0.81(0.77-0.84)$ \\
\hline $45-54$ & $1.01(0.98-1.04)$ & $0.80(0.76-0.83)$ \\
\hline $55-64$ & $0.90(0.87-0.93)$ & $0.75(0.72-0.78)$ \\
\hline $65-74$ & $0.43(0.41-0.44)$ & $0.40(0.38-0.43)$ \\
\hline$\geq 75$ & $0.31(0.29-0.33)$ & $0.33(0.31-0.36)$ \\
\hline $12-17$ & 1 & 1 \\
\hline \multicolumn{3}{|l|}{ Ethnicity } \\
\hline $\begin{array}{l}\text { Nonwhite (Aboriginal/other visible } \\
\text { minority) }\end{array}$ & $0.88(0.86-0.91)$ & $0.90(0.87-0.93)$ \\
\hline White & 1 & 1 \\
\hline \multicolumn{3}{|l|}{ Education } \\
\hline $\begin{array}{l}\text { Postsecondary certificate diploma/ } \\
\text { university degree }\end{array}$ & $1.36(1.33-1.40)$ & $1.29(1.24-1.34)$ \\
\hline $\begin{array}{l}\text { Secondary school graduation, no } \\
\text { postsecondary education }\end{array}$ & $1.14(1.11-1.18)$ & $1.19(1.14-1.24)$ \\
\hline Less than secondary school graduation & 1 & 1 \\
\hline \multicolumn{3}{|l|}{ Province } \\
\hline British Columbia & $0.97(0.94-1.00)$ & $0.99(0.96-1.01)$ \\
\hline Alberta & $1.16(1.14-1.19)$ & $1.05(1.03-1.08)$ \\
\hline Saskatchewan & $1.09(1.05-1.13)$ & $1.03(0.99-1.06)$ \\
\hline Manitoba & $1.10(1.06-1.14)$ & $1.09(1.05-1.13)$ \\
\hline Quebec & $0.94(0.92-0.97)$ & $0.96(0.94-0.99)$ \\
\hline New Brunswick & $1.11(1.07-1.16)$ & $1.15(1.11-1.20)$ \\
\hline Nova Scotia & $1.07(1.03-1.11)$ & $1.09(1.06-1.13)$ \\
\hline Prince Edward Island & $1.04(0.99-1.10)$ & $1.08(1.03-1.13)$ \\
\hline Newfoundland and Labrador & $1.06(1.01-1.11)$ & $1.08(1.04-1.13)$ \\
\hline Yukon Territory & $0.84(0.76-0.92)$ & $0.74(0.67-0.81)$ \\
\hline Northwest Territories & $1.06(0.96-1.17)$ & $0.82(0.74-0.91)$ \\
\hline Nunavut & $1.32(1.18-1.47)$ & $0.98(0.88-1.08)$ \\
\hline Ontario & 1 & 1 \\
\hline \multicolumn{3}{|l|}{ No. of chronic conditions } \\
\hline 1 & $0.92(0.91-0.94)$ & $1.00(0.98-1.02)$ \\
\hline$\geq 2$ & $0.72(0.71-0.74)$ & $0.96(0.94-0.98)$ \\
\hline 0 & 1 & 1 \\
\hline \multicolumn{3}{|l|}{ Citizenship } \\
\hline Nonimmigrant (Canadian born) & $1.19(1.15-1.22)$ & $1.05(1.02-1.09)$ \\
\hline $\begin{array}{l}\text { Landed immigrant/nonpermanent } \\
\text { resident }\end{array}$ & 1 & 1 \\
\hline
\end{tabular}




\begin{tabular}{|lcccc|}
\hline \multicolumn{4}{|l|}{ Table 3: Age-stratified adjusted prevalence ratio for holding private drug insurance } \\
\hline \multirow{4}{*}{$\begin{array}{l}\text { Annual household } \\
\text { income, } \$\end{array}$} & $12-17$ & $18-24$ & $25-64$ & $\geq 65$ \\
\cline { 2 - 5 } & \multicolumn{5}{c|}{ Age, yr; prevalence ratio $(95 \% \mathrm{Cl})$} \\
\hline $20000-39999$ & $1.23(0.94-1.61)$ & $1.06(0.88-1.28)$ & $1.84(1.60-2.12)$ & $1.96(1.59-2.43)$ \\
\hline $40000-59999$ & $1.79(1.41-2.29)$ & $1.18(0.99-1.41)$ & $2.92(2.55-3.34)$ & $3.34(2.70-4.13)$ \\
\hline $60000-79999$ & $2.20(1.73-2.79)$ & $1.28(1.07-1.52)$ & $3.40(2.97-3.89)$ & $3.99(3.21-4.96)$ \\
\hline$\geq 80000$ & $2.58(2.05-3.24)$ & $1.57(1.36-1.81)$ & $4.02(3.52-4.59)$ & $4.51(3.64-5.59)$ \\
\hline$<20000$ & 1 & 1 & 1 & 1 \\
\hline Note: $\mathrm{Cl}=$ confidence interval. & & & & \\
\hline
\end{tabular}

people who were not aware that they had it through workplace coverage plans. However, we note that our estimates of the proportion of the Canadian population covered by private insurance is roughly similar to estimates produced by the private insurance industry. ${ }^{22}$ We were also unable to assess the generosity of coverage and whether this varied between different groups. Finally, we did not study the factors associated with public insurance, as prior research has shown that people underreport this type of coverage significantly. ${ }^{17}$

\section{Conclusion}

We found significant income-related inequities in private drug insurance coverage in Canada. As insurance coverage has been shown to be associated with a greater ability to afford prescription medications, this may be contributing to differential access to medicines and health outcomes by different income groups.

\section{References}

1. Hurley J, Guindon E. Private health insurance in Canada. CHEPA Working Paper series paper 08-04. Hamilton (ON): Centre for Health Economics and Policy Analysis, McMaster University; 2008. Available: http://chepa.org/docs/ working-papers/chepa-wp-08-04-.pdf (accessed 2019 Feb. 1).

2. Prescribed drug spending in Canada, 2017: a focus on public drug programs. Ottawa: Canadian Institute for Health Information; 2017:49.

3. Tang KL, Ghali WA, Manns BJ. Addressing cost-related barriers to prescription drug use in Canada. CMA7 2014;186:276-80.

4. Colombo F, Tapay N. Private health insurance in OECD countries. The benefits and costs for individuals and health systems. Health Working Paper no. 15. Paris: Organisation for Economic Co-operation and Development; 2004.

5. Hurley J. Income and equity of access to physician services. CMA7 2006;174:187-8.

6. Fang H, Keane MP, Silverman D. Sources of advantageous selection: evidence from the Medigap insurance market. 7 Polit Econ 2008;116:303-350.

7. Locker D, Maggirias J, Quiñonez C. Income, dental insurance coverage, and financial barriers to dental care among Canadian adults: financial barriers to dental care. 7 Public Health Dent 2011;71:327-34.

8. Ngo G, Trope G, Buys Y, et al. Significant disparities in eyeglass insurance coverage in Canada. Can 7 Ophthalmol 2018;53:260-5.

9. Allin S, Hurley J. Inequity in publicly funded physician care: What is the role of private prescription drug insurance? Health Econ 2009;18:1218-32.

10. Kratzer J, Cheng L, Allin S, et al. The impact of private insurance coverage on prescription drug use in Ontario, Canada. Healthc Policy Polit Santé 2015;10:62-74.
11. Allin S, Law MR, Laporte A. How does complementary private prescription drug insurance coverage affect seniors' use of publicly funded medications? Health Policy 2013;110:147-55.

12. Law MR, Daw JR, Cheng L, et al. Growth in private payments for health care by Canadian households. Health Policy 2013;110:141-6.

13. Stabile $M$, Isabelle $M$. Rising inequality and the implications for the future of private insurance in Canada. Health Econ Policy Law 2018;13:406-32.

14. Law MR, Cheng L, Kolhatkar A, et al. The consequences of patient charges for prescription drugs in Canada: a cross-sectional survey. CMAF Open 2018;6: E63-70.

15. Morgan S. Prescription drug access and affordability an issue for nearly a quarter of all Canadian households [public opinion poll]. Angus Reid Institute; 2015 July 15. Available: http://angusreid.org/prescription-drugs-canada/print (accessed 2019 Feb. 1).

16. Schoen C, Davis K, DesRoches C, et al. Health insurance markets and income inequality: findings from an international health policy survey. Health Policy 2000;51:67-85.

17. Canadian Community Health Survey (CCHS) 2015-2016 User Guide.pdf. [restricted access]. Ottawa: Statistics Canada; 2017.

18. Grootendorst P, Newman E, Levine MAH. Validity of self-reported prescription drug insurance coverage. Health Rep 2003;14:35-46.

19. Chen W, Qian L, Shi J, et al. Comparing performance between log-binomial and robust Poisson regression models for estimating risk ratios under model misspecification. BMC Med Res Methodol 2018;18:63.

20. Barros AJ, Hirakata VN. Alternatives for logistic regression in cross-sectional studies: an empirical comparison of models that directly estimate the prevalence ratio. BMC Med Res Methodol 2003;3:21.

21. Zou G. A modified Poisson regression approach to prospective studies with binary data. Am 7 Epidemiol 2004;159:702-6.

22. Akyeampong EB. Unionization and fringe benefits. In: Perspectives on labour and income. Ottawa: Statistics Canada; 2002. Cat no 75-001-XIE.

Affiliation: Centre for Health Services and Policy Research, School of Population and Public Health, University of British Columbia, Vancouver, BC

Contributors: Talshyn Bolatova conceived of the study, acquired and analyzed the data, and drafted the manuscript. Michael Law designed the study, interpreted the data and critically revised the manuscript for important intellectual content. Both authors approved the final version to be published and agreed to act as guarantors of the work.

Funding: This analysis was funded by Foundation Grant FDN-148412 from the Canadian Institutes of Health Research to Michael Law. Michael Law received salary support through a Canada Research Chair and a Michael Smith Foundation for Health Research Scholar Award.

Supplemental information: For reviewer comments and the original submission of this manuscript, please see www.cmajopen.ca/content/7/4/ E618/suppl/DC1. 